\title{
El vicio de incongruencia en laudos extranjeros, inejecutabilidad por violación al orden público ecuatoriano
}

\begin{abstract}
Cuando la ley y la fuerza mantienen a un hombre dentro de la justicia, no le imponen otra cosa que pura negación. No le imponen más que la abstención de dañar a otros. No atentan ni contra su personalidad, ni contra su libertad, ni contra su propiedad. Tan solo salvaguardan la personalidad, la libertad y la propiedad de los demás.
\end{abstract}

Frederic Bastiat

Luis Eduardo Narváez* María Belén Merchán**

Sumario: 1. Introducción. 2. Tutela Arbitral Efectiva y Debido Proceso. 2.1. Principio Dispositivo. 2.2. Principio de Congruencia. 2.3. Tipos de Vicios de Incongruencia. 2.3.1. Por Omisión o Citrapetita. 2.3.2. Ultra Petita. 2.3.3. Extra Petita. 2.3.4. Por Error. 3. Nulidad de laudos en Ecuador. 4. Ejecución de laudos extranjeros con vicios de incongruencia en Ecuador. 4.1. Laudos no anulables con vicios de incongruencia, ¿existen?. 4.2. Situación actual en Ecuador: ¿homologación o ejecución directa de laudos extranjeros?. 4.3. Violación al orden público ecuatoriano de un laudo extranjero no anulado con vicios de incongruencia. 5. Conclusiones.

Resumen: Los laudos emitidos en el contexto de un arbitraje internacional pueden en ciertos casos adolecer de vicio de incongruencia. Bajo la mirada de la lex arbitri aplicable a cada caso en particular, estos laudos, en virtud de la interpretación

* Director Legal Latam de Synlab Latam. Abogado por la Universidad San Francisco de Quito, Master in Law.por Cornell Law School.

** Socia del Estudio Jurídico Quevedo-Ponce, Secretaria arbitral del Centro de Arbitraje y Mediación de la Cámara de Comercio de Quito. Abogada por la Pontificia Universidad Católica del Ecuador con certificación en Especialización en Habilidades en Litigio por Washington College of Law, American University. 
restrictiva que se debe dar a las causales de nulidad y el principio de trascendencia, podrán o no ser anulados en la sede del arbitraje. No obstante, en virtud de la aplicación del artículo V de la Convención de Nueva York, el vicio de incongruencia de un laudo arbitral podría ser causal para la oposición al reconocimiento y ejecución del laudo en el Ecuador. Esto, en virtud de que el principio de congruencia es parte de los derechos de Tutela Arbitral Efectiva y Debido proceso, garantías constitucionales básicas en el Ecuador que forman parte del orden público ecuatoriano.

Palabras Clave: Principio de Congruencia, Laudos Extranjeros, Homologación, Ejecución, Orden Público.

\section{The vice of inconsistency in foreign awards, unenforceability due to violation of Ecuadorian public order}

Aвstract: Foreign Arbitral Awards can have vices, incongruencies that opose the congruence principle. These viced international awards depending on the grounds for nullity determined on the applicable lex arbitri, the application of the nullity transcendence principle and the restrictive interpretation of the nullity grounds can be subject to nullity actions. Nullified or not on the place of arbitration, recognition and enforcement of foreign arbitral award can be refused in Ecuador under the application of article $\mathrm{V}$ of the New York Convention. Mainly because constitutional rights of due process and effective arbitral protection cover the congruence principle, these rights are part of the Ecuadorian Public Policy.

Keywords: Congruence Principle, Foreign Arbitral Awards, Recognition and Enforcement of Foreign Arbitral Awards, Public Policy

\section{INTRODUCCIÓN}

En la antigua Roma, a partir del período denominado extraordinaria cognitio, se modifica la naturaleza del proceso judicial en donde hasta esa fecha era predominantemente 
dispositivo a un sistema inquisitivo. La importancia del juez pasó a ser trascendental, el mismo empieza a predominar en su investidura y es quien dirige el proceso de principio a fin. Autores como Vescovi describen a este periodo como el periodo en el cual el procedimiento "se vuelve escrito, la publicidad cede paso al secreto, la mediación sustituye a inmediación" ${ }^{1}$, el Magistrado se torna en un verdadero protagonista del proceso; "los tribunales juzgan por encargo del emperador, es natural que este se reserve la última instancia" 2 . Entonces es aquí en donde se reglamenta que le corresponde al juez delimitar el marco del proceso y, al ser el juez quien conducía el proceso podía incluir, investigar y agregar sus propias pretensiones a la causa bajo análisis. Posteriormente, toma relevancia la actuación de las partes marcando al principio dispositivo como un principio fundamental del derecho civil. Es así que el juez puede ejercer su tutela jurisdiccional únicamente cuando las partes lo solicitan y se ve abocado a respetar los límites impuestos por ellas para resolver el objeto del proceso, siendo imprescindible que la resolución sea congruente con las pretensiones de las partes.

El término incongruencia proviene del Latín "incongruentia" y tiene un significado negativo al significar falta de congruencia. Para la Real Academia Española congruencia se define como "conveniencia, coherencia y relación lógica" 3 . En la psicología la congruencia es la correlación que existe entre el sentimiento y la expresión. Carl Rogers uno de los exponentes de la escuela humanista de la Psicología define a la congruencia en este sentido:

[E]xiste un estado de congruencia cuando las experiencias simbolizadas de una persona reflejan todas las experiencias reales del organismo. Cuando estas vivencias simbolizadas no representan todas las reales, o si son negadas o distorsionadas, hay una falta de correspondencia entre el yo como es percibido y el yo real. En tal situación hay incongruencia y una posible desadaptación... Cuando el auto concepto es congruente con las experiencias del organismo, la persona

1. E. VESCOVI. “Teoría General del Proceso", Segunda Edición Actualizada, Editorial Temis, 2006.

2. Ídem.

3. Diccionario de la Real Academia Española, <https://dle.rae.es/congruencia >, (21/07/2021). 
está libre de la tensión interna y adaptada desde el punto de vista psicológico ${ }^{4}$.

En el contexto de este artículo se revisará brevemente el derecho a la tutela arbitral efectiva y debido proceso, para luego analizar el alcance del principio dispositivo en el sistema arbitral y el principio de congruencia aplicable al proceso. Revisaremos en qué consiste el principio de congruencia y cuáles son los diferentes tipos de vicios de incongruencia. Estudiaremos, si la violación al principio de incongruencia por ser parte de los derechos de tutela arbitral efectiva y debido proceso puede usarse como fundamento para oponerse al reconocimiento y ejecución de un lado extranjero en el Ecuador por violación al orden público ecuatoriano. Finalmente, este artículo presenta la premisa de que, si bien en la sede se puede anular o no el laudo según la lex arbitri, en virtud del artículo V de la Convención de Nueva York la violación al orden público del lugar de ejecución sí es causal de inejecutabilidad del laudo, aunque no haya sido declarado nulo.

\section{TUtela ARBITRAL EFECTIVA Y DEBIDO PROCESO}

El arbitraje, al ser un método alternativo y heterocompositivo útil para resolver controversias, debe contener en su proceso las actuaciones necesarias que aseguren el cumplimiento y aplicación de los derechos y garantías de las partes. En su deber de procurar un laudo válido y ejecutable, los árbitros, tras un análisis a la legislación aplicable al caso, deberán garantizar que los derechos de las partes sean respetados durante el procedimiento. Normalmente, las causales de nulidad, y en el caso de laudos extranjeros las de denegación de reconocimiento y/o ejecución, procuran que el laudo, para que sea válido y ejecutable, haya respetado estas normas básicas o derechos mínimos de las partes durante el proceso. El carácter jurisdiccional del arbitraje, fruto de su reconocimiento en la norma constitucional ${ }^{5}$, e incluso el reconocimiento específico

4. C. Rogers. La relación interpersonal: núcleo de la orientación. Incluído en C. Rogers, B. STEVENS, et al, "Persona a persona". Buenos Aires: Amorrortu, en $<$ https://glosarios.servidor-alicante.com/psicologia/congruencia $>$, (21/07/2021).

5. Art. 190.- Se reconoce el arbitraje, la mediación y otros procedimientos alternativos para la solución de conflictos. Estos procedimientos se aplicarán con sujeción a la ley, en materias en las que por su naturaleza se pueda transigir. 
contenido en el Código Orgánico de la Función Judicial ${ }^{6}$, de que los árbitros ejercen funciones jurisdiccionales los obliga a que, en ejercicio del derecho a tutela efectiva, la sustanciación del proceso arbitral se realice precautelando las garantías básicas contenidas en la Constitución.

La tutela arbitral efectiva es un derecho constitucional de protección derivado de la tutela judicial efectiva, pero aplicable al proceso arbitral. En términos prácticos hablamos del mismo derecho aplicado a las particularidades del proceso arbitral. La Constitución de la República garantiza el derecho a la tutela judicial efectiva en los siguientes términos: "toda persona tiene derecho al acceso gratuito a la justicia y a la tutela, efectiva imparcial y expedita de sus derechos e intereses, con sujeción a los principios de inmediación y celeridad; en ningún caso quedará en indefensión". El derecho a la tutela arbitral efectiva es un principio fundamental para la administración de justicia o el órgano jurisdiccional. Para nuestra Corte Constitucional el derecho "comprende no solo el acceso a la justicia, sino también, el desarrollo del proceso con la debida observancia de normas constitucionales y legales y la ejecución de la sentencia; es decir, el derecho a obtener una decisión judicial motivada y que sea ejecutada"7. En otras decisiones la Corte ha dispuesto que este derecho tiene relación con:

[E]l derecho de acceso a los órganos jurisdiccionales para que, luego de un proceso que observe las garantías mínimas establecidas en la Constitución y en la ley, se haga justicia; por tanto, se puede afirmar que su contenido es amplio y en este se diferencian tres momentos: el primero relacionado con el acceso a la justicia, el segundo con el desarrollo del proceso en un tiempo razonable, y el tercero que tiene relación con la ejecución de la sentencia, esto es, acceso a la jurisdicción, debido proceso y eficacia de la sentencia ${ }^{8}$.

Para Salcedo Verduga, por ejemplo, el hecho de que las partes en virtud del principio de autonomía de la voluntad

6. Art. 7.- Principios de legalidad, jurisdicción y competencia. - (...) Los árbitros ejercerán funciones jurisdiccionales, de conformidad con la Constitución y la ley.

7. Corte Constitucional. Consulta de Norma. Caso No. 13-17-CN, Registro Oficial Edición Constitucional No. 21, 13 de noviembre 2019.

8. Corte Constitucional. Sentencia No. 030-SCN-CC, Registro Oficial Suplemento No. 359, 10 de enero 2011. 
excluyan sus conflictos de la justicia ordinaria no significa de modo alguno que ellas renuncian a la cobertura de sus derechos constitucionales básicos, como son el debido proceso y la tutela judicial efectiva por ser estos de carácter irrenunciable9. En el derecho comparado, en especial en el latinoamericano, el derecho a la tutela judicial efectiva es de vital importancia, así, la Corte Constitucional colombiana ha dispuesto que el derecho a la tutela judicial efectiva involucra "el derecho a que la promoción de la actividad jurisdiccional concluya con una decisión de fondo en torno a las pretensiones que han sido planteadas"10. Resulta fundamental para nuestro análisis identificar que de acuerdo al pronunciamiento de la Corte Constitucional colombiana y lo expuesto por la ecuatoriana el principio dispositivo y el principio de congruencia forman parte de las garantías o elementos del derecho a la tutela judicial efectiva.

El debido proceso es otro de los derechos involucrados en el arbitraje. Siendo no muy distinto al anterior, se lo puede considerar una especie del mismo género, por cuanto en el sistema de origen continental la tutela judicial efectiva es un abanico más amplio de garantías a las contenidas en el debido proceso. Autoras como Jara Vásquez acaparan ambos principios y lo diferencian por su origen: "El derecho a la tutela efectiva y el debido proceso provienen de distintas tradiciones jurídicas. El primero, de fuente europea (...). El segundo, se originó en el common law -due process of law-, y sus antecedentes se suelen ubicar en la Carta Magna inglesa de $1215^{\prime 11}$. No obstante, el contenido del derecho al debido proceso en el derecho anglosajón es mucho más amplio que el conferido en tradiciones civilistas. A saber, de la misma autora, el due process del Common Law es mucho más amplio en contenido que el derecho a la tutela judicial efectiva ${ }^{12}$. Evidentemente, dentro del derecho al debido proceso tenemos algunos principios considerados en nuestra Constitución como son el principio de contradicción y el derecho

9. E. Salcedo Verduga. El Arbitraje: La Justicia Alternativa. 1ra edición, Cevallos Editorial Jurídica, 2001.

10. Corte Constitucional de Colombia. Sentencia No 435/2002. Citado en: Corte Constitucional Ecuador, sentencia No. 034-09-SEP-CC, Registro Oficial Suplemento No. 97 de 29 de diciembre de 2009.

11. M. E. Jara VÁsquez. La Tutela Arbitral Efectiva en Ecuador. 1ra Edición. Corporación de Estudios y Publicaciones, 2017.

12. Ídem. 
a la defensa que tiene una relación estrecha con el principio de congruencia analizado en este artículo.

La Corte Constitucional ecuatoriana ha expresado que en el proceso arbitral también se deben garantizar los derechos reconocidos en la norma constitucional. El análisis de este particular se ha centrado en que, al igual que el proceso judicial, el arbitraje es un método heterocompositivo de resolución de controversias. Aunque el arbitraje deviene principalmente del principio de la autonomía de la voluntad, en el Ecuador tiene una fuente legal y constitucional. En este sentido, el acuerdo arbitral, el proceso, y el laudo, no pueden contradecir normas constitucionales o dictaminar renuncia de derechos contenidos en la Constitución. Por lo mismo, "los convenios arbitrales, el proceso de arbitraje y su conclusión, están limitados y vinculados por las normas constitucionales, al igual que todas las relaciones jurídicas y actos públicos y privados, más allá de que su origen pueda considerarse convencional"13. El debido proceso, como es evidente, tiene una estrecha relación en el arbitraje con el principio dispositivo y el principio de congruencia puesto que "obliga a las autoridades públicas a guardar coherencia entre los hechos y el derecho aplicado en la toma de decisiones respecto de su autoridad"14.

\subsection{Principio dispositivo}

Tradicionalmente, la aplicación del principio dispositivo se da cuando las partes inician un proceso judicial y con ello delimitan el objeto de la controversia en el planteamiento de sus pretensiones. Por esto se dice que el principio dispositivo es uno de los fundamentos del principio de congruencia. El arbitraje está marcado también por el principio dispositivo en base a las pretensiones dentro de los límites de lo que se conoce como arbitrabilidad objetiva. El principio dispositivo es el que "asigna a las partes y no al juez, la iniciativa del proceso, el ejercicio y el poder de renunciar a los actos del proceso"15. El principio dispositivo a diferencia del inquisitorio

13. Corte Constitucional, Acción Extraordinaria de Protección. Sentencia No. 169-12-SEP-CC, Registro Oficial Suplemento No. 756 de 30 de julio de 2012.

14. Corte Constitucional, Acción Extraordinaria de Protección. Sentencia No. 169-12-SEP-CC, Registro Oficial Suplemento No. 756 de 30 de julio de 2012.

15. E. Vescovi. N. 1. 
o el mixto es característico del proceso civil y por lo tanto, por la naturaleza de las pretensiones y características del proceso arbitral.

Para Vescovi, el principio dispositivo está conformado de varios subprincipios: i) nemo iudex sine actore ne procedat iure ex officio, que significa que no hay juicio sin actor y el juez no puede iniciarlo de oficio, es decir, el proceso debe iniciar por iniciativa de las partes y no puede iniciar de oficio. De este nace el principio de congruencia, en virtud del cual el objeto del proceso es fijado por las partes, es decir, se delimita en virtud de lo solicitado por el actor y lo aceptado o denegado por el demandado y las pruebas vertidas por cada uno de ellos en defensa de sus pretensiones. El juez "no conoce otros hechos fuera de los que las partes invocan, ni otras pruebas que las que estas presentan"16. Bajo esta premisa, el juez debe resolver sobre lo que las partes pidan y no más allá. Aunque el juez puede en virtud del principio Iura Novit Curia modificar en el caso de error u omisión el derecho invocado por las partes, pero no conceder bajo este entendimiento más, menos o algo diferente de lo pedido. El tercer principio, que está conectado también a los dos anteriores, es que los recursos, solo los pueden deducir las partes y “el tribunal superior no tendrá más facultades de revisión que aquellas que han sido objeto del recurso"17. El cuarto principio es que las partes pueden disponer del propio proceso "esto es de los derechos sustanciales planteados durante el mismo; ya sea del actor desistiendo de su pretensión, el demandado allanándose a ella, realizando una transacción, en la cual ambos se hacen concesiones recíprocas" 18 .

No es posible afirmar que dada la naturaleza y estructura única del procedimiento arbitral, el principio dispositivo sea idéntico al del proceso civil, mucho más si lo analizamos en el contexto de un arbitraje internacional. Ciertos autores han reconocido que son los árbitros en realidad y no las partes quienes fijan el objeto del proceso. La delimitación por supuesto se la realiza sobre la base de las pretensiones aducidas por las partes, las normas procesales, procedimentales y sustantivas a los que están sujetos. Normalmente, deberíamos encontrar la solución clara a esta problemática en las normas que la mayoría de lex arbitri otorgan para formular las

16. Ídem.

17. Ídem.

18. Ídem. 
normas de procedimiento ${ }^{19}$. En ciertos reglamentos, por ejemplo, las pretensiones y objeto del proceso se fijan en el acta de misión y a falta de acuerdo entre las partes sobre la misma, como menciona el Reglamento la Corte Internacional de Arbitraje, puede el tribunal aprobarla y delimitar el objeto del proceso para que el arbitraje continúe su curso ${ }^{20}$.

Existe otro segmento de la doctrina que determina que, en virtud del principio de la autonomía de la voluntad, son las partes quienes delimitan el objeto del proceso. En esta línea argumentativa cabe señalar que, en términos prácticos, son las partes quienes precisan sus pretensiones. En Ecuador, se realiza en la audiencia de sustanciación. A falta de disposición en la lex arbitri, debe observarse los reglamentos, por ejemplo, en la aprobación del acta de misión, según el de la CCI. Podría decirse, por lo tanto, que son las partes quienes en último término disponen cual será el objeto del Litis. La determinación del procedimiento como facultad prevista en ciertas lex arbitri así como la facultad del tribunal de delimitar el objeto y sujetarlo a aprobación de las partes no es un determinante per se para decir que son los árbitros quienes delimitan el objeto. Esta propuesta de delimitación deberá basarse en todo momento en las pretensiones aducidas en la demanda y contestación.

\subsection{Principio de congruencia}

El uso del concepto congruencia no tiene grandes variaciones en su esencia etimológica o psicológica cuando lo estudiamos en la ciencia del Derecho. La congruencia constituye uno de los pilares del principio dispositivo. Si nos situamos en materia, en el proceso judicial "podemos entender la congruencia como la correlación

19. A modo de ejemplo tenemos el artículo 25.2 de la Ley de Arbitraje Española donde se dispone que "A falta de acuerdo, los árbitros podrán, con sujeción a lo dispuesto en esta Ley, dirigir el arbitraje del modo que consideren apropiado. Esta potestad de los árbitros comprende la de decidir sobre admisibilidad, pertinencia y utilidad de las pruebas, sobre su práctica, incluso de oficio, y sobre su valoración" o en el Caso de Ecuador por ejemplo se está a lo dispuesto en el artículo 38.

Ciertos Reglamentos como CCI determinan que son los árbitros quienes delimitan el proceso en las actas de misión, son las partes las llamadas a corregir esta fijación o pedir se incorporen o eliminen asuntos no propuestos por ellas. El reglamento de la CCI incluso permite que en la emisión del laudo se determine un término para que las partes puedan solicitar se incluyan puntos omitidos o no se decida sobre puntos no discutidos.

20. Reglamento CCI. Artículo 23, 2021. 
debida entre la actividad procesal de las partes y la actividad del órgano judicial" ${ }^{21}$. Esta correlación deriva de lo que las partes han delimitado como objeto del proceso o theme decidendum que es el marco, el espacio real fijado por las partes con sus pretensiones, dentro del cual el juez deberá emitir su decisión. Todo lo que el juez decida que no se encuentre dentro del objeto del proceso puede acarrear que la decisión esté viciada de incongruencia.

Para que la administración de justicia cumpla su función, existen ciertos principios o garantías esenciales que deben respetarse en el proceso, estos principios tienen su fundamento en axiomas primarios de justicia. Estos principios regulan la conducta de las partes, los jueces, o los árbitros dentro de un proceso y que en muchos casos varían dependiendo de la materia de la que trate. Otros son comunes a todos los procesos, uno de esos axiomas transversales de la administración de justicia es el principio de congruencia.

Son las partes las que, tras presentar demanda, contestación, o reconvención; durante la audiencia de sustanciación podrán precisar las pretensiones y hechos en las que estas se fundamentan. Consideramos que la precisión de las pretensiones es el momento en el que será posible concretar el theme decidendum. No obstante lo anterior, entendemos que, en términos prácticos es posible que el tribunal arbitral considere sugerir a las partes cuál es la materia controvertida para que la misma quede delimitada precisamente como lo dispone el art. 22 de la LAM. Las partes, por su lado, podrán precisarlo conforme lo dispone el mismo artículo. De esta forma se ha sugerido, por ejemplo, que en el arbitraje internacional:

El acta de misión establece preponderantemente la ruta crítica del procedimiento arbitral, esto es, refiere sucintamente cuáles son las pretensiones de las partes; el lugar o sede del arbitraje; la indicación de las reglas aplicables al procedimiento y las precisiones que las partes o el tribunal consideran relevantes a fin de resolver adecuadamente la controversia planteada; de estar contemplada la redacción de esta acta de misión y determinarse la aceptación de su contenido por las partes, cobra validez probatoria para establecer cuál es la intención

21. M.E. Alegret Burges. "El principio de congruencia en el proceso arbitral", <https://vlex.es/ $\mathrm{vid} /$ principio-congruencia-procedimiento-arbitral-585724230>, (21/07/2021). 
de aquéllas (sic) para ocurrir al procedimiento y sujetar la controversia concreta a unas determinadas reglas ${ }^{22}$.

Considerando esta aclaración, es apropiado analizar si encontramos la solución a la problemática dentro del resto de normativas relevantes aplicables. El art. 38 de la LAM dispone que el arbitraje "se sujetará a las normas de procedimiento señaladas en la ley, al procedimiento establecido en los centros de arbitraje, al determinado en el convenio arbitral o al que las partes escojan". No se ha encontrado, por ejemplo, en el reglamento de la Cámara de Comercio de Quito, ninguna disposición relativa a la fijación del objeto de la pretensión por parte de los árbitros. Por otra parte, el Reglamento de la CCI determina una aprobación forzosa del acta de misión a falta de acuerdo o firma conforme lo explicamos en el acápite anterior.

Aunque no sea deseable, se debe acudir al Código Orgánico General de Procesos (COGEP), norma supletoria para el arbitraje. En el mismo, es claro que en el proceso civil, rige a plenitud el principio de congruencia y el mismo se encuentra consagrado en su art. 90, cuando dispone que "las sentencias deberán ser claras, precisas y congruentes con los puntos materia del proceso. Resolverán sobre las peticiones realizadas por las partes y decidirán sobre los puntos litigiosos del proceso". En conclusión, de aplicarse la lex arbitri ecuatoriana a un arbitraje internacional, el objeto del proceso será delimitado por las partes, aunque los árbitros, en la audiencia de sustanciación o acta de misión, podrán sugerir o proponer a las partes el objeto del proceso siempre dentro del marco de la autonomía de la voluntad.

Partiendo de estas premisas, es claro que si el árbitro o tribunal deciden emitir un laudo arbitral incongruente, cuando "omita pronunciarse sobre cuestiones que hayan sido debatidas en el juicio" ${ }^{23}$, o cuando se conceda más de lo pedido, algo diferente a lo pedido o cuando el razonamiento es errado sobre una pretensión ajena al objeto; se puede decir que dicho laudo posee un vicio de incongruencia.

22. Centro de Arbitraje de México. Tercer Tribunal Colegiado en Materia Civil del Primer Circuito, $<\mathrm{https} / /$ camex.com.mx/2018/03/06/principio-de-congruencia-en-el-procedimiento-arbitral-se-limita-por-la-clausula-arbitral-y-el-acta-de-mision/>, (26/07/2021).

23. "Incongruencia de las Sentencias". https://bit.ly/3vJWSgo, (26/07/2021). 
La importancia de la protección en el ordenamiento jurídico se observa en que la incongruencia es incluso una de las causales para interponer un recurso de casación de acuerdo al COGEP. Así, el art. 268 de este cuerpo legal determina que serán objeto de recurso de casación las sentencias que "cuando se haya resuelto en la sentencia o auto lo que no sea materia del litigio o se haya concedido más allá de lo demandado, o se omita resolver algún punto de la controversia".

En el arbitraje la incongruencia en ciertas lex arbitri pueden acarrear la nulidad del laudo. En el caso de Ecuador, la LAM en su art. 31.d, prevé la nulidad cuando el laudo se refiera a cuestiones no sometidas al arbitraje o conceda más allá de lo reclamado. Conforme a las últimas resoluciones de la Corte Constitucional también puede caber acción extraordinaria de protección por violación por acción u omisión de derechos reconocidos en la Constitución como el debido proceso para laudos domésticos. Por otra parte, tratándose de laudos extranjeros conforme lo determina el artículo 5 de la Convención de Nueva York sobre el Reconocimiento y Ejecución de las Sentencias Arbitrales Extranjeras (Convención de Nueva York) se podrá denegar el reconocimiento o ejecución cuando se pruebe "que el reconocimiento o ejecución de la sentencia sean contrarios al orden público del país de ejecución", si el laudo extranjero tiene un vicio de incongruencia contiene una violación a principios fundamentales del derecho interno y confluye en violación al orden público.

A nivel constitucional existen algunos pronunciamientos relativos al principio de la congruencia y su importancia. Así, la Corte Constitucional ha afirmado que la violación al principio de congruencia constituyeuna violaciónalos principios constitucionales de debido proceso, derecho a la defensa y seguridad jurídica. "La finalidad del principio de congruencia consiste entonces en evitar arbitrariedades de parte de las autoridades jurisdiccionales, impidiendo que, dentro de las decisiones judiciales, se dictaminen cuestiones que no han sido debidamente invocadas por las partes procesales" ${ }^{24}$. En este sentido:

24. Corte Constitucional. Chevron c. Corte Nacional de Justicia. Causa No. 0105-14-EP, Registro Oficial Edición Constitucional No. 84, 14 de mayo 2019. 
[E]l principio de congruencia es entendido como el principio normativo que exige la identidad jurídica entre lo resuelto, en cualquier sentido por el juez en la sentencia y las pretensiones o excepciones planteadas por las partes, también entre la sentencia y lo ordenado por la ley que sea resuelto de oficio por el juzgador, de esta manera en función del principio de congruencia la actividad jurisdiccional se encuentra limitada a emitir un pronunciamiento únicamente respecto a las pretensiones de la parte actora en relación a las excepciones o contestación por la contraparte, constituyendo así, un verdadero principio regulador de las facultades resolutivas de los jueces. La congruencia es entonces un principio procesal que constituye una especie del género del debido proceso. ${ }^{25}$

Existen pocas referencias respecto a los pedidos de anulación por vicios de incongruencia de los laudos arbitrales. Normalmente, en el ámbito de sus competencias, el árbitro procurará emitir laudos válidos y ejecutables. Arroyo, Suárez y Rivadeneira, tras una investigación profunda de acciones de nulidad presentadas ante la Corte Provincial sobre el vicio de incongruencia ultra petita en la cuantía, señalaron: "como se puede evidenciar, las cortes ecuatorianas se han negado a declarar la nulidad de laudos arbitrales por el vicio de incongruencia ultra petita"26. La Corte Nacional de Justicia en un análisis de la aplicabilidad del principio de congruencia en el arbitraje en equidad determinó en una de sus resoluciones que a pesar de la naturaleza propia de los arbitrajes en equidad ello no implica "resolver cuestiones no sometidas al arbitraje o conceder más allá de lo reclamado lo que en definitiva concuerda con el principio de congruencia, que rige al proceso y que debe ser rigurosamente observado en una resolución de árbitros en derecho" ${ }^{\prime 27}$.

En la LAM, solo el vicio de incongruencia ultra petita es causal de anulación de los laudos arbitrales. ¿Qué sucede con otros tipos de incongruencias? A priori podría decirse que tratándose de laudos locales lo que procedería es la Acción Extraordinaria de

25. Ídem.

26. C. Arroyo, L. Suárez, G. Rivadeneira. "La Cuantía en la Demanda Arbitral, un limitante a los derechos de reparación". Revista Ecuatoriana de Arbitraje, No. 9, 15 de noviembre de 2018.

27. Corte Nacional de Justicia. Recurso de Hecho en Contra de Sentencia denegatoria de Nulidad del Laudo, Transinvest S.A. Seguranza Cia. Ltda. y Metromedical Cia. Ltda., Juicio No. 572007-k.r, Expediente de Casación 51, Registro Oficial Edición Especial 416, (25/03/2013). 
Protección por violación a las garantías del debido proceso y tutela arbitral efectiva que cubren al principio dispositivo y al principio de congruencia. Tratándose de laudos extranjeros a ejecutarse en el Ecuador, solo es posible oponerse a la ejecución del laudo incongruente, como ya lo veremos más adelante, en aplicación del artículo V de la Convención de Nueva York por ser el laudo contrario al orden público, pues la falta de congruencia en el laudo implica violación a los principios básicos que rigen el derecho interno y a su vez, como es lógico, violación de los derechos al debido proceso y tutela judicial efectiva.

\subsection{Tipos de vicios de incongruencia}

Normalmente, hay dos clases generales de incongruencia, la interna y la externa. Podríamos decir que la primera tiene una relación estrecha con la sentencia o laudo arbitral y en este sentido, hay incongruencia cuando la parte resolutiva de la decisión no tiene una relación lógica o coherencia con la parte considerativa. Así, la decisión "adolece de una inadecuación lógica de los fundamentos que desarrolla en su texto con la decisión que al final adopta en base a ellos" ${ }^{\prime 28}$. Dentro de este tipo de incongruencia podemos encontrar a los subtipos de incongruencia: por error y en la reforma peyorativa o reformatio in peius en apelación, lo que no será motivo de análisis en este artículo. La segunda clase, por su parte, tiene relación con la decisión y lo pedido por las partes, la Corte Constitucional ha dicho "que consiste en la concordancia que debe haber entre las pretensiones de la demanda, los medios de defensa deducidos por la parte demandada y la resolución" ${ }^{29}$. Normalmente, dentro de este tipo de incongruencia, podemos encontrar a los subtipos de incongruencia por omisión o citrapetita, cuando se concede más de lo pedido o ultra petita y cuando se concede algo distinto a lo pedido extra petita.

\subsubsection{Por omisión o citrapetita}

La incongruencia por omisión ocurre cuando el juez o el árbitro omite resolver sobre alguna de las pretensiones alegadas por las

28. "Incongruencia de las Sentencias". N. 23.

29. Corte Constitucional. Pabucorp c. Sala de Civil y Mercantil de la Corte Nacional de Justicia. Caso No. 0965-13-EP, Registro Oficial Edición Constitucional No. 41, 10 de abril de 2018. 
partes. Resulta importante recalcar que negar una pretensión no es omitir la resolución sobre algún asunto determinado. No obstante, no cualquier omisión puede viciar una decisión de incongruencia citrapetita y así también lo afirma la doctrina:

[N]o toda omisión puede conducir a un reproche de incongruencia. No todos los supuestos son susceptibles de una solución unívoca, debiendo ponderarse las circunstancias concurrentes en cada caso para determinar si el silencio de una resolución judicial constituye una auténtica lesión (...) si, por el contrario, puede razonablemente interpretarse como una desestimación tácita que satisfaga las exigencias del derecho a la tutela judicial efectiva. ${ }^{30}$

Es claro que la omisión debe necesariamente resultar material para la decisión, lesionar a las partes, dejarlas en indefensión y ser determinante para el objeto de la controversia, para poder ponderar adecuadamente la gravedad, y por lo mismo las consecuencias como la anulación o inejecutabilidad del laudo por este tipo de incongruencia. La materialidad del vicio o su gravedad como es posible observar es concordante con el principio de trascendencia aplicable a la nulidad.

El recurso procesal común frente a la incongruencia omisiva debería ser el de ampliación. En términos del COGEP, en su art. 253, procede el recurso de aclaración y ampliación: "cuando no se haya resuelto alguno de los puntos controvertidos o, se haya omitido decidir sobre frutos, intereses o costas". En el arbitraje, procede recurso de ampliación y aclaración luego de los tres días de notificado el laudo a las partes. En este sentido, en arbitrajes locales no procede anulación por incongruencia omisiva sino recurso de aclaración y ampliación. Lo mismo es aplicable en arbitrajes extranjeros en donde rija lex arbitri ecuatoriana.

El reglamentoarbitrajedela Cámara deComercioInternacional ${ }^{31}$, por su parte, dispone que sobre el laudo cabría corrección de oficio ante error de tipo tipográfico, cálculo etc., solitud de laudo adicional o solicitud de interpretación del laudo. Entonces, cabría solicitud

30. A. Orena Domínguez. Clases de Incongruencia, <https://vlex.es/vid/clases-incongruencia-434262750>, (26/07/2021).

31. Reglamento CCI. Artículo 36. 
de laudo adicional si el tribunal no se hubiere pronunciado sobre algún asunto controvertido en el proceso, es decir, hay un nivel de protección contra el vicio citrapetita. Entendemos, por ejemplo, que para vicios extra petita, ultra petita o error, procedería la interpretación del laudo e incluso la solicitud de corrección "error, de cálculo o tipográfico o de naturaleza similar", si es que se tratara de un asunto menor que evidencia un error formal, pero que acarrea el laudo esté viciado de incongruencia.

\subsubsection{Ultra petita}

La incongruencia ultra petita se da cuando la sentencia o laudo concede más de lo pedido por las partes. Como la anterior, deberá analizarse con cautela caso por caso para entender hasta qué punto el vicio en la sentencia o laudo constituye una verdadera violación al orden público ecuatoriano. Normalmente, podemos encontrar al vicio de ultra petita cuando el juzgador incurre en exceso de poder $\mathrm{y}$, como es obvio, es común encontrar este fallo en exceso cuando se reconoce, por ejemplo, al actor más de lo que él mismo pide en la demanda. Ya se mencionó que el vicio de incongruencia ultra petita es una causal de anulación del laudo de acuerdo con la LAM. No obstante Arroyo, Suárez y Rivadeneira en una investigación realizada a las sentencias en casos de procesos de nulidad encontraron que:

Después de realizar un análisis de 41 procesos de nulidad de laudos arbitrales, pudimos concluir que 33 de estas acciones se han fundamentado en la causal prevista en el literal d) del artículo 31 de la LAM, la cual establece que se podrá intentar la acción de nulidad cuando: "[...] el laudo se refiera a cuestiones no sometida a arbitraje o conceda más allá de lo reclamado". No obstante, de los 33 casos que se han fundamentado en esta causa, únicamente en seis de ellos se han basado en el vicio de incongruencia ultra petita. ${ }^{32}$

Ninguna de estas acciones ha prosperado concluyen las autoras pues la Corte ha considerado que los tribunales arbitrales "han resuelto analizando las pretensiones, excepciones y pruebas

32. C. Arroyo, L. Suárez, G. Rivadeneira. N. 26. 
que han sido presentadas por las partes dentro del proceso arbitral y que, por lo tanto, no existe vicio de incongruencia ultra petita." ${ }^{\prime 3}$

\subsubsection{Extra petita}

La incongruencia extra petita consiste en conceder algo a las partes que fue pedido por las mismas dentro del proceso. En este sentido, la jurisprudencia comparada ha determinado que se incurre en el vicio "cuando el órgano judicial concede algo no pedido o se pronuncia sobre una pretensión o una causa de pedir que no fue oportunamente deducida por los litigantes ${ }^{\prime 34}$. Resulta fundamental aclarar que este tipo de incongruencia pueden invocarse como tal, cuando no se trata de pretensiones o excepciones que, aunque no formalmente deducidas por las partes, se encuentran implícitas en lo pedido o eran una consecuencia natural de los fundamentos principales aducidos por las partes. Entre algunos de los ejemplos de lo que no podría ser reconocido como incongruencia extra petita tenemos por ejemplo el hecho de haber otorgado intereses tras reconocer una deuda dineraria.

\subsubsection{Por error}

La incongruencia por error contiene algunos subtipos. Sin embargo, para efectos de este artículo se hará referencia únicamente a la categoría genérica. Se entiende que se incurre en este tipo de incongruencia cuando "por error de cualquier género sufrido por el órgano judicial, no se resuelve sobre la pretensión formulada en la demanda o sobre el motivo del recurso, sino que equivocadamente se razona sobre una pretensión absolutamente ajena al debate procesal planteado" ${ }^{\prime 35}$.

Una vez establecidos los diferentes tipos de incongruencia, en la siguiente sección se analizará la procedencia de la nulidad al existir incongruencia en el laudo y en el evento de que el laudo no sea anulado la posibilidad de oponerse en el proceso de reconocimiento y ejecución del laudo.

\footnotetext{
33. Ídem.

34. "Incongruencia de las Sentencias". N. 23.

35. Ídem.
} 


\section{Nulidad de laudos en Ecuador}

El convenio arbitral tiene como característica la obligación a la que se someten las partes de no acudir a la justicia ordinaria antes y durante el desarrollo del proceso arbitral para someter cualquier tema de fondo del contrato (incumplimiento, interpretación, etc.). La excepción está en ciertos temas como validez de cláusula arbitral, la nulidad del laudo y su ejecución. Es así que el control judicial del laudo nace como excepción al contrato de arbitraje de las partes y solo se presentará ex post al laudo, sea como un recurso de nulidad, o como oposición al reconocimiento y ejecución del laudo. La amplia aplicación de lo referido por la Ley Modelo de CNUDMI ${ }^{36}$, en razón de las causales de nulidad, ha hecho que exista uniformidad sobre cuándo aplicar las cláusulas taxativas.

Múltiples legislaciones han acogido las causales de nulidad de la Ley Modelo ${ }^{37}$. En Ecuador, las causales de nulidad son: i) No se haya citado legalmente con la demanda y el juicio se ha seguido y terminado en rebeldía. Será preciso que la falta de citación haya impedido que el demandado deduzca sus excepciones o haga valer sus derechos y, además, que el demandado reclame por tal omisión al tiempo de intervenir en la controversia; ii) No se haya notificado a una de las partes con las providencias del tribunal y este hecho impida o limite el derecho de defensa de la parte; iii) Cuando no se hubiere convocado, no se hubiere notificado la convocatoria, o luego de convocada no se hubiere practicado las pruebas, a pesar de la existencia de hechos que deban justificarse; iv) El laudo se refiera a cuestiones no sometidas al arbitraje o conceda más allá de lo reclamado; o, v) Cuando se hayan violado los procedimientos previstos por esta Ley o por las partes para designar árbitros o constituir el tribunal arbitral.

Dentro de la causal iv) de la ley arbitral ecuatoriana, encontramos que la Corte puede resolver sobre una nulidad que emerge en un laudo en el que se resolvió más allá de lo autorizado por las partes en el convenio arbitral. La segunda parte de esa causal, esto es, cuando el laudo conceda más allá de lo reclamado, alude al

36. Art. 34 de la Ley Modelo de la Comisión de las Naciones Unidas sobre Arbitraje Comercial Internacional de 1965, enmendada en el 2006.

37. Legislaciones como la chilena, peruana y argentina han incorporado la normativa Ley Modelo. 
vicio de incongruencia extra o ultra petita, sobre este vicio la corte provincial analizará si el tribunal otorgó más de lo solicitado en la pretensión o si se refirió a algo que no estaba contenido en el pedido de la parte. Las cortes provinciales han resuelto en varios casos la procedencia de la causal al establecer que el tribunal se refirió a aspectos no referidos por las partes o excedió en sus atribuciones para establecer reparaciones punitivas.

Las causales de nulidad taxativas conllevan que de forma excepcional el juez de la sede revise errores que pudieron haberse cometido en el desarrollo del proceso, de ahí que las causales antes detalladas se refieren a vicios procesales que deviene en un debido proceso defectuoso que restringe los derechos de las partes. Por ello, la revisión restringida del laudo en una acción de nulidad no podrá alcanzar el fondo del mismo y en caso de encontrar la procedencia de la nulidad deberá procurarse declararla solo de la parte que corresponde anular.

Conforme a la doctrina, la nulidad reviste la obligación de ponderar al menos tres principios: i) Trascendencia: la nulidad alegada debe mostrar que ha afectado de forma sustancial al proceso y en consecuencia a las partes. "Es decir, que la causa de nulidad esté expresamente consignada como tal en la norma jurídica y que dicho motivo hubiese influido o podido influir en la decisión de la controversia de modo trascendente como cuando se ha afectado el derecho a la defensa de una de las partes." ${ }^{38}$; ii) Especificidad: la alegación de nulidad debe estar plenamente justificada únicamente bajo cualquier causal que la ley arbitral determine, aunque en la práctica jurisprudencial tanto de sentencias emitidas por las cortes provinciales como por la Corte Constitucional pueden hallarse diversas interpretaciones a qué se considera causal de nulidad; y, iii) Convalidación: pueden surgir actos procesales que no puedan ser convalidados en el proceso y que necesariamente deban ser corregidos por el juez. Importante destacar que la parte que alega la nulidad no puede servirse de ella si en el desarrollo del proceso mostró su acuerdo con las decisiones procesales del tribunal arbitral.

38. Corte Nacional de Justicia, Sala de lo Civil y Mercantil, juicio No. 077-2011, sentencia de 8 de agosto de 2012. 
Es posible, entonces, que un laudo con vicio de incongruencia revisado bajo ley ecuatoriana pueda ser anulado. Como hemos visto es causal de nulidad en Ecuador que el laudo sea incongruente por extra o ultra petita. Es decir, solo si la ley de la sede es la ley ecuatoriana un juez podría revisar la acción de nulidad de un laudo extranjero por incongruente por extra o ultra petita, pero ¿qué ocurre con un laudo extranjero con vicio de incongruencia no anulado y que busca ser ejecutado en Ecuador?

\section{EJECUCIÓN DE LAUdOS EXTRANJEROS CON VICIOS DE INCONGRUENCIA EN ECUADOR}

\subsection{Laudos extranjeros no anulables con vicios de incon- gruencia ¿existen?}

Evidentemente, la complejidad de la normativa aplicable a los procedimientos arbitrales conlleva que se presenten casos en los cuales, mientras para una legislación un laudo es válido, para otra legislación puede no ser aceptada su incorporación al ordenamiento jurídico doméstico.

El art. 34 de la Ley Modelo señala que el laudo arbitral solo podrá ser anulado cuando se comprueben las causales determinadas en dicha norma referencial. Legislaciones como la chilena, peruana, española y argentina han adoptado este texto. En ese sentido, si un juez de la sede fijada para el arbitraje internacional resuelve que el laudo no tiene vicios de nulidad, podría ser declarado válido y en consecuencia ser ejecutado en el lugar que más convenga a la parte a la cual favorece el laudo. En nuestra jurisdicción ya existe un caso que puede ser usado como cuestionamiento a si un laudo con vicio de incongruencia no anulado en sede puede ser ejecutado en Ecuador y que se lo revisa a continuación.

El 1 de abril de 2011, la empresa holandesa CW Travel Holdings NV (CWT) y la empresa ecuatoriana Seitur Agencia de Viajes y Turismo (SEITUR), celebraron un acuerdo de asociación que autoriza a la empresa SEITUR y a sus agencias la venta de viajes en el Ecuador. Después de varios conflictos y la imposibilidad de que SEITUR recupere la acreditación de Asociación Internacional 
de Transporte Aéreo, el 15 de marzo de 2012, CWT envió una carta a SEITUR para romper el acuerdo de asociación. El 6 de noviembre de 2012, SEITUR implementó el procedimiento de arbitraje celebrado bajo los auspicios de la Cámara de Comercio Internacional.

En laudo emitido el 7 de abril de 2015, el tribunal arbitral compuesto por Alexis Mourre y Armando Serrano Puig, árbitros, y Claus Von Webeser, Presidente, se declararon competentes para conocer el litigio. El tribunal arbitral confirmó la validez de la anulación del acuerdo de sociedad por parte de CWT, ordenó a SEITUR que cesara de inmediato el uso del nombre y de las marcas comerciales de CWT, bajo una penalidad de US $\$ 10.000$ por día de retraso, y sentenció a SEITUR a pagar por costas la suma de US $\$ 567,987$ con un pago de la tasa de interés de $2 \%$ que comienza a correr el día que se pronuncie la sentencia. SEITUR interpuso un recurso de anulación en contra de dicha sentencia, el 3 de abril de 2017. La demanda de nulidad del laudo fue negada por la Corte de Apelaciones de París. Se encuentra pendiente un recurso de casación ${ }^{39}$. Más adelante se revisará el vicio de incongruencia que contiene el laudo a pesar de ser válido para la ley francesa hasta este momento.

\subsection{Situación actual en Ecuador: ¿homologación o ejecución directa de laudos extranjeros?}

El Código Orgánico General de Procesos fue reformado dos veces por el legislador. La primera reforma fue en la Ley de Fomento de Inversiones de agosto de 2018, y la segunda reforma se dio por el Art. 64 de la Ley reformatoria del citado Código promulgada en el Registro Oficial No. 517 el 26 de junio de 2019. Aún con esas dos reformas, el legislador mantuvo el requisito de que el laudo extranjero debe ser homologado para luego ser ejecutado. Es indudable que el legislador decidió, con todo el conocimiento debido, dejar el requisito de que el laudo extranjero ha de ser homologado y de acuerdo a la legislación actual debe efectuarse a través de procedimiento ordinario.

39. Corte Internacional de Arbitraje. CW Travel Holdings NV c. Seitur Agencia de Viajes y Turismo, Laudo $\mathrm{N}^{\circ}$ 19058/GFG. 
La disposición contenida en el art. 363 numeral 5 del COGEP ya ha sido aplicada por la Sala Civil de la Corte Provincial de Pichincha en el proceso de ejecución No. 17230-2019-03159. En este caso la corte resolvió negar la ejecución del laudo extranjero por no encontrarse homologado ${ }^{40}$. Es claro entonces que, al no haber un proceso especial para la homologación, esto debe realizarse mediante procedimiento ordinario en aplicación del art. 289 del código procesal.

Otro proceso que ratifica actualmente en Ecuador el hecho de que se requiera homologación del laudo extranjero previo a su ejecución es la resolución emitida por un juez civil en un caso de medidas cautelares en el cual se pidió prohibición de enajenar inmuebles para luego presentar demanda de ejecución del laudo emitido en Nueva York bajo reglas CCI. El juez resolvió que debía aplicarse la legislación vigente y por lo tanto el laudo para ser título de crédito válido y ejecutable debe ser primero homologado. La parte actora no apeló de esta sentencia.

No cabe duda, entonces, que en este momento en el Ecuador si se pretende ejecutar un laudo extranjero deberá primero ser homologado mediante procedimiento ordinario. Es entonces en el proceso de homologación en el que la parte a la cual se le ejecutará el laudo debe oponerse a que este sea incorporado al ordenamiento jurídico ecuatoriano. Es importante indicar que el hecho de que el laudo sea sometido a un proceso de homologación no garantiza de ninguna forma que este vaya a ser homologado. En el proceso de homologación el juez está obligado a verificar que el laudo no viola el orden público ecuatoriano, si encuentra una sola violación no podrá ser incorporado al ordenamiento jurídico y por lo tanto no podrá ser como título de ejecución.

\subsection{Laudo extranjero no anulado con vicios de incongruencia que viola el orden público ecuatoriano.}

La Convención de Nueva York, aplicable al reconocimiento y ejecución de laudos extranjeros, prescribe en su artículo V, numeral

40. Sala de lo Civil de la Corte Provincial de Pichincha. Proceso de ejecución N ${ }^{\circ}$ 17230-201903159 . 
2 liberal b) que: “También se podrá denegar el reconocimiento y la ejecución de una sentencia arbitral si la autoridad competente del país en que se pide el reconocimiento y la ejecución, comprueba:... b) Que el reconocimiento o la ejecución de la sentencia serían contrarios al orden público de ese país". En el ejemplo del caso CWT c. SEITUR antes referido, del laudo se desprende que se rechazó la demanda de CWT íntegramente como se expresa en los párrafos 322 y 323 que dice:

322. El Tribunal Arbitral ha analizado la demanda y ha determinado que CWT no ha podido probar que los supuestos daños realmente surgieron de los incumplimientos al Contrato por parte de SEITUR. La Demandante únicamente presentó una sola página titulada "Estado de daños y perjuicios incurridos por CWT" en la que CWT explica que gastó US\$ 18.500 en viajes del personal de CWT para capacitar al personal de SEITUR. Sin embargo, no existe ningún compromiso en el Contrato que obligue a CWT no explica por qué esos gastos de viaje pueden traducirse en daños y perjuicios o cómo esos gastos pueden vincularse en alguna forma a los incumplimientos de SEITUR. 323. Con relación a los US\$26.506 que CWT tuvo que pagar como multas a sus clientes debido a que SEITUR no aplicó las tarifas correctas al reservar viajes, el Tribunal determina que CWT no pudo probar que esa suma fue realmente pagada a los clientes de CWT supuestamente perjudicados y que CWT nuevamente solo presentó un único papel en el que alega, sin ningún fundamento ulterior, que pagó esas multas a sus clientes. Lo que, es más, el "Estado de Daños y Perjuicios incurridos por CWT" no menciona cuáles clientes de CWT fueron perjudicados.

Sin embargo, en contra de toda racionalidad y, naturalmente, en contra de cualquier orden público el laudo en vez de rechazar en su integridad la demanda por falta de prueba condenó a SEITUR a pagar los costos de arbitraje, los honorarios de los abogados de CWT y multas por US\$21.000 diarios que CWT nunca pidió como indemnización de daños y perjuicios por el uso de marcas y nombre de dominio sino que requirió como medida cautelar para que SEITUR cesara provisionalmente en el uso de dichas marcas y nombre de dominio. En efecto, se condenó a la demandada al pago de las siguientes cantidades desproporcionadas: 
a) Penalidades judiciales por US\$ 10.000 diarios que no fueron solicitadas en la demanda arbitral contenido en el párrafo 342 del laudo;

b) US\$10.000 por día hasta que cese el uso de la señalética y marcas de CWT contenido en el párrafo 348 del laudo;

c) US\$ 1.000 por día hasta que el nombre de dominio de CWT retorne a CWT contenido en el párrafo 348 del laudo;

d) Costo de arbitraje establecido por la Corte Internacional de Arbitraje de la CCI en US\$180.000, párrafo 346 de laudo;

e) US\$ 387.987 de honorarios de los abogados de CWT, párrafo 347 del laudo; $y$,

f) $2 \%$ de intereses anual por sobre los montos arriba mencionados contenido en el párrafo 349 del laudo.

Es decir, SEITUR fue condenado al pago de US\$21.000 diarios a pesar de que el Tribunal arbitral determinó que no había daños probados por parte de CWT, lo que convierte al laudo con vicio de incongruencia por ultra petita al dar más allá de lo solicitado por CWT.

SEITUR dejó de usar la señalética y marcas de CWT cuando comenzó el proceso arbitral, por lo que el laudo no podía imponer a SEITUR multas diarias por US\$ 10.000. Lo propio ocurre con el nombre de dominio de CWT el cual pertenece a CWT y, por lo tanto, SEITUR de ninguna forma estaría obligada a pagar una multa de US\$ 1.000 diarios.

El presente caso es único en el Ecuador al ser el primer antecedente que se registra sobre la pretensión de ejecutar un laudo extranjero que lesiona gravemente los derechos de una compañía ecuatoriana al otorgar cientos de veces más de lo demandado.

La Corte Nacional de Justicia, ha definido a la incongruencia como:

[U]n error in procedendo que tiene tres aspectos: a) Cuando se otorga más de lo pedido (plus o ultra); b) Cuando se otorga 
algo distinto a lo pedido (extrapetita); c) Cuando se deja de resolver sobre algo pedido (citrapetita). Entonces como instrumento de análisis, el defecto procesal de incongruencia debe resultar de la comparación entre el petitorio de la demanda y la parte dispositiva de la sentencia, lo cual ha de estar perfectamente explicitado en la fundamentación del recurso. ${ }^{41}$

Sobre dicha base ha declarado que no cabe, en sentencia, dar más de lo reclamado en la demanda.

La Corte Suprema de Justicia también había decidido:

De lo antes dicho podemos inferir que el principio de congruencia o armonía del fallo se contrae a la necesidad de que este se encuentre en consonancia con las pretensiones deducidas por el demandante en la demanda, o en las demás oportunidades que la ley le ofrece para proponerlas; y con las excepciones que aparezcan probadas, y hubieran sido invocadas por el demandado, si no se autoriza su declaración oficiosa. O sea que el juez en su sentencia, tiene que pronunciarse sobre todo lo que se ha pedido por los litigantes y solamente sobre lo demandado; pero, además, su decisión no puede fundarla sobre hechos que no están en el debate. ${ }^{42}$

La decisión ultra petita, deviene entonces en la inexistencia de la resolución, pues si no hay proceso sin demanda, no puede haber laudo sin demanda.

Es, pues, un principio incuestionable de orden público en el Ecuador el que jamás un fallo, sea judicial o arbitral, puede dar más de lo reclamado. En este laudo, que podría ejecutarse por parte de CWT, esa transgresión es total y evidente. Si el laudo no fue anulado bajo la ley de su sede de ninguna forma limita a que este deba pasar por un control de legalidad en el proceso de homologación. Es precisamente el proceso de reconocimiento del laudo el que precautela que no se incorpore al ordenamiento jurídico doméstico

41. Corte Nacional de Justicia, Sala de lo Civil y Mercantil. Anexo 10, literal k, 21 de septiembre de 2014, Prophar S.A. v. Merck Sharp \& Dohme (Inter American) Corporation, Gaceta Judicial serie XVIII. No. 12, p. 4336.

42. Corte Suprema de Justicia, Tercera Sala de lo Civil y Mercantil. Anexo 10, literal 1, 25 de enero de 2007, Víctor Hugo Tapia Bajaña c. Compañía Aseguradora del Sur C.A., Gaceta Judicial serie XVIII. No. 3, p. 884. 
laudos que vulneren el derecho fundamental al debido proceso de la parte contra la cual se ejecuta.

En el Ecuador, pues, es un principio inconcuso de nuestra jurisprudencia que los jueces no pueden otorgar más de lo reclamado en la demanda. Este es un principio de orden público que no puede violarse porque constituye una de las "cuestiones consideradas por el derecho interno como ineludiblemente sometidas a este mismo derecho interno", de acuerdo con la definición doctrinal del maestro Juan Larrea Holguín ${ }^{43}$, quien, adicionalmente considera que son parte del orden público las normas que atañen, entre otras materias, las relacionadas con la estructura de "los derechos" pues el orden público se halla constituido por las "condiciones y circunstancias básicas de una sociedad para que se respeten en ella los derechos individuales y colectivos, se mantenga la paz y la seguridad" ${ }^{\prime 4}$. Altera estas condiciones sociales esenciales un laudo que otorgue más de lo reclamado en la demanda.

De otro lado, además de la jurisprudencia ecuatoriana ya citada, en varios laudos extranjeros se analiza y reconoce que el reclamante que ha tenido éxito en establecer la responsabilidad civil debe establecer el quantum de sus demandas al estándar pertinente de la prueba y para obtener las sumas en cuestión ellas no deben ser especulativas ni demasiado remotas ${ }^{45}$.

Así, por ejemplo, internacionalmente se ha resuelto que "si bien es cierto que tales daños no necesitan ser probados con certeza matemática, tampoco pueden establecerse mediante pruebas que

43. J. Larrea Holguín. Enciclopedia Jurídica Ecuatoriana, Tomo X, "Voces de derecho internacional privado", Fundación Latinoamericana Andrés Bello, Quito, 2006, p. 341.

44. J. Larrea Holguín. Enciclopedia Jurídica Ecuatoriana, Tomo IX, "Voces de derecho civil", Quito, 2005, p. 216.

45. S.D. Myers, Inc (SDMI) v. Gobierno de Canadá. CIADI. Segundo Laudo Parcial de 21 de octubre de 2002. Texto original: 173. The quantification of loss of future profits claims can present special challenges. On the one hand, a claimant who has succeeded on liability must establish the quantum of his claims to the relevant standard of proof; and, to be awarded, the sums in question must be neither speculative nor too remote. On the other hand, fairness to the claimant requires that the court or tribunal should approach the task both realistically and rationally. The challenges become more acute in start-up situations where there is little or no relevant track record. El laudo hace un examen minucioso de las pruebas aportadas por las partes sobre la procedencia de daños y la cuantía, dichas pruebas incluyen informes de peritos expertos y detalles de estados contables. 
sean especulativas y conjeturales" 46 , y menos aún puede ordenarse el pago de daños y perjuicios sobre los cuales no existe demostración alguna.

En definitiva, las decisiones en arbitrajes internacionales, inclusive los arbitrajes internacionales de inversión, no constituyen procedimientos excluidos de los límites razonables que cualquier juez común debe tener al momento de emitir su decisión sobre el monto de la indemnización por daños y perjuicios dentro de los límites invocados por las propias partes.

\section{Conclusiones}

Es claro que un laudo puede ser anulado o no por vicios de incongruencia. En el escenario de que el juez de la sede considere que no hay vicios puede resolver que el laudo es válido y por lo tanto deberá ser considerado así por las partes. Sin embargo, debido a la diversidad de legislaciones y aplicación de normativas puede ser el caso que el laudo aún declarado válido en sede arbitral contenga vicios de incongruencia que deban ser verificados por el juez del lugar donde va a ejecutarse el laudo.

La Convención de Nueva York no presenta una definición de orden público pues son las legislaciones locales las que deben delimitar qué consideran por orden público y en consecuencia qué lo puede violentar. Conforme se ha analizado ampliamente en la primera parte de este estudio, el principio dispositivo y el principio de congruencia forman parte de las garantías o elementos del derecho a la tutela judicial efectiva y de forma más amplia el debido proceso. En el Ecuador el principio de congruencia deriva directamente del ejercicio del derecho al debido proceso y por tanto constituye norma básica a ser respetada por sentencias o laudos aún si son extranjeros.

La ejecución de laudos extranjeros en el Ecuador hasta este momento tiene como requisito que el laudo esté debidamente

46. N. Steinkamp et al. The Journal of Damages in International Arbitration. JurisNet. Vol. 2, No. 1, p. 29. 2015. Cita 21. Texto original: "While it is true that such damages need not be proved with mathematical certainty, neither can they be established by evidence which is speculative and conjectural" (Lloyd supra at 37 (citing Katskee v. Nev. Bob's Golf of Neb., Inc., 472 N.W.2d 372, 379) Neb.1991). 
homologado. Es en el momento de la homologación en el cual la parte afectada deberá oponerse por violación al debido proceso al existir vicio de ultra petita y en consecuencia violación al orden público, conforme al artículo V de la Convención de Nueva York. Dentro del proceso de homologación, la demostración de violación al orden público determinará que el laudo no pueda ser reconocido en el Ecuador, impidiendo cualquier tipo de ejecución. ${ }^{47}$

El respeto a la institución arbitral conlleva la aplicación de los principios de favorabilidad e inevitabilidad. No obstante, es también fundamental constituir una justicia arbitral que si presenta fallas en sus resoluciones pueda ser analizada por el juez competente, en procura del efectivo ejercicio de los derechos al debido proceso y a la defensa de las partes en el arbitraje.

47. Al momento de la entrega de este artículo académico entró en vigencia el Reglamento a la Ley de Arbitraje y Mediación contenido en el decreto ejecutivo No. 165 de 18 de agosto de 2021, publicado en el Registro Oficial 524 de 26 de agosto de 2021. En su art. 15 numeral 1 se indica que para la ejecución de laudo internacionales no se requerirá de un procedimiento previo de homologación. Sin embargo, de conformidad con el art. 425 de la Constitución, un reglamento por su jerarquía no puede reformar el Código Orgánico General de Procesos, por lo que la norma procesal en su art. 363 numeral 5 continua vigente, esto es, el laudo extranjero para ser título de ejecución debe estar homologado. Más aún, la reforma de normativa orgánica de acuerdo al Artículo 120 numeral 6 es una facultad de la Asamblea Nacional, siendo imposible que un reglamento emita una reforma de ley. 


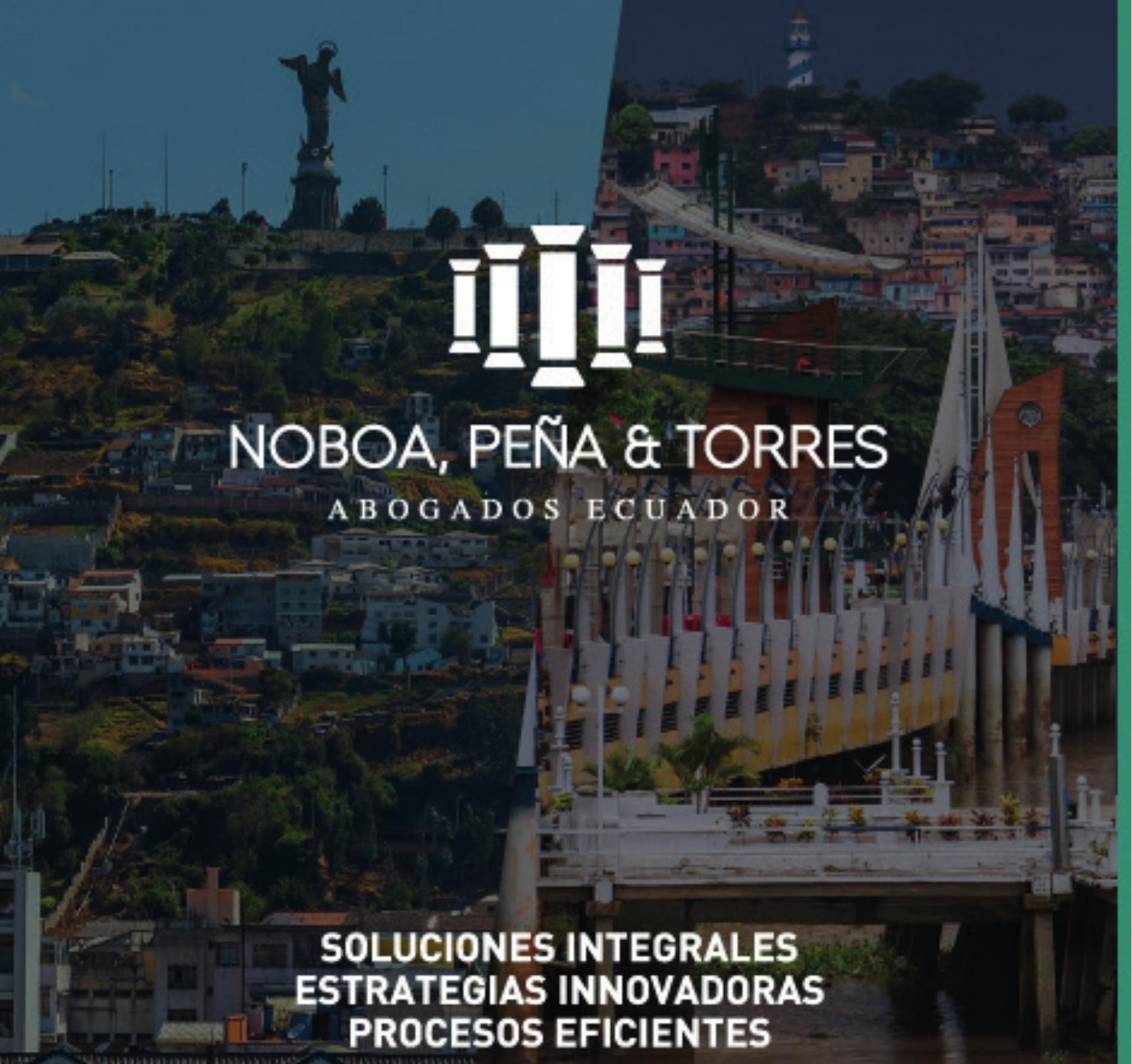


